\title{
Analisis Video Likes To Likes Rasio TikTok Pada Top 5 Vendor Smartphone di Indonesia
}

\author{
I Wayan Herry Indra Wijaya \\ STMIK STIKOM Indonesia \\ herryindra22@gmail.com
}

\begin{abstract}
TikTok is a social media application that allows users to create 15 -second videos with music, filters, and other creative features. This application was launched by a company from China, China, ByteDance first launched an application that has a short duration called Douyin. In Indonesia alone there were 22.2 million active users last year which provides a huge opportunity for various brands to market their products through TikTok. There are various types of brands that have used the TikTok application to promote their products, for example, smartphone vendors in Indonesia. Of the many smartphone vendors, the Top 5 Smartphone Vendors in Indonesia in Q2 are: XIAOMI Indonesia, Oppo Indonesia, Samsung Indonesia, REALME Indonesia and VIVO Indonesia. The purpose of this study is to determine the credibility of the TikTok accounts of the 5 Smartphone Vendor in Indonesia on Q2 2021. The method used in this study is a quantitative exploratory method. The results of this study indicate that the Samsung Indonesia account has the best performance credibility and is ranked first among the five smartphone vendor accounts.
\end{abstract}

\begin{abstract}
ABSTRAK
TikTok merupakan aplikasi media sosial yang memungkinkan penggunanya membuat video berdurasi 15 detik disertai musik, filter, dan beberapa fitur kreatif lainnya. Aplikasi ini diluncurkan oleh perusahaan asal Tiongkok, China, ByteDance pertama kali meluncurkan aplikasi yang memiliki durasi pendek yang bernama Douyin. Di Indonesia sendiri terdapat 22,2 juta pengguna aktif tahun lalu yang memberikan peluang yang sangat besar bagi berbagai brand untuk memasarkan produknya lewat TikTok. Ada berbagai jenis brand yang telah menggunakan aplikasi TikTok untuk mempromosikan produknya, contohnya adalah vendor vendor smartphone di Indonesia. Dari sekian banyak vendor smartphone, Top 5 Vendor Smartphone di Indonesia pada Q2 yaitu : XIAOMI Indonesia, Oppo Indonesia, Samsung Indonesia, REALME Indonesia dan VIVO Indonesia. Tujuan penelitian ini adalah mengetahui nilai kredibilitas akun TikTok 5 Vendor Smartphone di Indonesia Q2 2021. Metode yang digunakan dalam penelitian ini adalah metode eksploratif kuantitatif. Hasil penelitian ini menunjukkan bahwa akun Samsung Indonesia memiliki kredibilitas performa terbaik dan memperoleh peringkat pertama di antara kelima akun vendor smartphone.
\end{abstract}

Kata Kunci : Kredibilitas Akun TikTok ; Social Media Marketing ; Video Likes to Likes ; Vendor Smartphone Indonesia ; Social Media TikTok. 


\section{PENDAHULUAN}

Perkembangan teknologi informasi dan komunikasi yang pesat telah mempermudah orang untuk berkomunikasi dengan orang lain dari jarak yang sangat jauh melalui media sosial. Seiring perkembangannya media sosial telah banyak mempengaruhi kehidupan manusia, seperti kemudahan dalam berinteraksi dengan banyak orang, membagikan informasi dengan mudah, belajar dan bermain serta sebagai hiburan. Penggunaan media sosial menjadi semakin mudah dengan dikembangkannya aplikasi yang dapat digunakan dengan mudah oleh orang awam.

Perkembangan teknologi media sosial yang semakin pesat telah memberikan dampak yang sangat besar bagi platform atau situs penyedia media sosial. Media sosial yang awalnya hanya digunakan untuk mengirim pesan sekarang dapat digunakan untuk berbagi informasi dan media hiburan. Salah satu aplikasi media sosial yang sedang banyak digunakan adalah aplikasi TikTok. TikTok merupakan aplikasi media sosial yang memungkinkan penggunanya membuat video berdurasi 15 detik disertai musik, filter, dan beberapa fitur kreatif lainnya. Aplikasi ini diluncurkan oleh perusahaan asal Tiongkok, China, ByteDance pertama kali meluncurkan aplikasi yang memiliki durasi pendek yang bernama Douyin. Hanya dalam waktu 1 tahun, Douyin memiliki 100 juta pengguna dan 1 miliar tayangan video setiap hari (Adawiyah, 2020).

Kehadiran aplikasi TikTok yang digunakan sebagai media hiburan dan kreativitas dapat membantu sebuah brand mempromosikan dan membangun basis penggemar di media sosial. Indonesia merupakan pasar kedua terbesar TikTok di dunia pada 2020. Melansir dari Statista, ada 22,2 juta pengguna aktif bulanan (monthly active users/MAU) aplikasi video pendek tersebut di tanah air pada tahun lalu (Indonesia Jadi Pasar Kedua Terbesar TikTok Di Dunia Pada 2020 | Databoks, n.d.). Dengan banyaknya pengguna aktif di Indonesia memberikan peluang yang sangat besar bagi berbagai brand untuk memasarkan produknya lewat TikTok. Ada berbagai jenis brand yang telah menggunakan aplikasi TikTok untuk mempromosikan produknya, contohnya adalah vendor - vendor smartphone di Indonesia. Dari sekian banyak vendor smartphone, Top 5 Vendor Smartphone di Indonesia pada Q2 yaitu : XIAOMI Indonesia, Oppo Indonesia, Samsung Indonesia, REALME Indonesia dan VIVO Indonesia (Top 5 Vendor Smartphone Di Indonesia Q2-2021 - Selular.ID, n.d.).

Penelitian ini berdasar pada penelitian (I Putu Hendika Permana \& Ni Putu Suci Meinarni, 2021) yang menggunakan metode eksploratif untuk menemukan variabel yang terdapat dalam akun Tiktok. Variabel-variabel ini akan dibandingkan untuk mencari rasio yang relevan untuk menunjukkan kinerja akun Tiktok. Hasil dari penelitian ini (I Putu Hendika Permana \& Ni Putu Suci Meinarni, 2021) adalah bahwa akun TikTok memiliki 7 variabel dan temukan 17 rasio yang dapat digunakan untuk menilai, mengukur, dan bandingkan kredibilitas akun Tiktok. Penelitian ini hanya berfokus untuk menghitung kredibilitas Video Likes to Likes pada Top 5 Vendor Smartphone di Indonesia. Tujuan dari penelitian ini adalah mengetahui kredibilitas dari akun TikTok Top 5 Vendor Smartphone di Indonesia menggunakan Video Likes to Likes Rasio. 


\section{TINJAUAN PUSTAKA}

Melalui perkembangan teknologi yang pesat terutama di bidang informasi telah melahirkan banyak aplikasi dan platform media sosial yang inovatif. Aplikasi media sosial saat tidak hanya digunakan untuk mengirim pesan, banyak aplikasi media sosial yang memberikan banyak fitur seperti berbagi status atau informasi serta mengepos dan menonton video. Salah satu media sosial yang terkenal belakangan ini adalah TikTok.

Pada aplikasi TikTok ini pengguna dapat membuat video yang hanya berdurasi kurang lebih 15-30 detik dengan memberikan special effects instan pada video yang unik dan menarik serta memiliki dukungan musik dari artis terkenal yang banyak sehingga penggunanya dapat melakukan performa dengan beragam gaya ataupun tarian, dan masih banyak lagi sehingga mendorong kreativitas penggunanya menjadi content creatore (Susilowati, 2018).

Sepanjang kuartal pertama (Q1) 2018, TikTok mengukuhkan diri sebagai aplikasi paling banyak diunduh yakni 45,8 juta kali. Jumlah itu mengalahkan aplikasi popular lain semacam YouTube, WhatsApp, Facebook Messenger, dan Instagram. Mayoritas dari pengguna aplikasi TikTok di Indonesia sendiri adalah anak milenial, usia sekolah, atau biasa dikenal dengan generasi Z (Wijaya \& Mashud, 2020).

Salah satu ciri khas media sosial TikTok adalah halaman utama yang bernama For You Page atau FYP. Pengguna yang sering ditayangkan dalam FYP dapat menjadi populer dan memiliki banyak pengikut. Dalam halaman ini setiap video unggahan pengguna lain baik yang diikuti maupun tidak, dapat ditayangkan sesuai video yang paling disukai dan ditonton oleh pengguna tersebut (Putri \& Azeharie, 2021).

Selain digunakan untuk membuat dan membagikan konten video, aplikasi TikTok saat ini juga digunakan untuk social media marketing. Para pengguna TikTok yang kebanyakan berasal dari kalangan remaja serta dewasa muda (sekitar 16-24 tahun) merupakan salah satu audiensi yang bagus untuk pemasaran di TikTok yang mana pemasaran yang sangat potensial bagi sebuah produk. Mengingat terdapat fitur-fitur pendukung yang ada di aplikasi TikTok yang dapat membuat suatu konten bisa lebih menarik dan mudah untuk dipasarkan (Hilal Ramadhan et al., 2021).

TikTok yang memiliki pengaruh besar dalam industri marketing menyebabkan adanya kualitas akun yang menentukan strata maupun kredibilitas pemilik akun. Kredibilitas sebuah akun TikTok dapat diukur dari tingkat performa yang dihasilkan secara matematis. Dalam mengukur performa diperlukan skala pengukuran yang tertuang ke dalam rasio. 


\section{METODE PENELITIAN}

Penelitian ini menggunakan metode eksploratif kuantitatif untuk mengetahui kredibilitas akun TikTok 5 Vendor Smartphone di Indonesia Q2 2021. Penelitian tipe eksploratif bertujuan memperdalam pengetahuan dan mencari ide-ide baru mengenai suatu gejala tertentu, menggambarkan fenomena sosial, dan menjelaskan bagaimana terjadinya suatu fenomena sosial untuk merumuskan masalah secara lebih terperinci atau mengembangkan hipotesis bukan menguji hipotesis (Mudjiyanto, 2018).

Tujuan penelitian ini adalah mengetahui nilai kredibilitas akun TikTok 5 Vendor Smartphone di Indonesia Q2 2021. Dalam penelitian ini ada beberapa langkah yang perlu dilakukan untuk menemukan peringkat pertama akun TikTok Vendor Smartphone di Indonesia dengan performa terbaik. Langkah - langkah yang dilakukan pada penelitian ini, di antaranya yaitu :

\section{Penentuan Objek yang Akan Dianalisis dengan Eksplorasi Website}

Langkah yang pertama dilakukan adalah mencari informasi mengenai objek yang diteliti melalui beberapa website. Setelah informasi mengenai objek yang diteliti ditemukan maka dilakukan pengecekan nama akun TikTok Vendor Smartphone untuk memastikan jika semua vendor memiliki akun TikTok.

\section{Menghitung Nilai Rata Variabel Dari Top 5 Vendor Smartphone di Indonesia}

Langkah selanjutnya adalah menghitung nilai rata dari variabel video likes dan likes. Untuk menghitung nilai rata dari video likes adalah dengan mengambil 10 postingan terakhir setiap akun yang kemudian dihitung untuk menemukan nilai rata dari variabel ini dan untuk jumlah likes diambil pada profil setiap akun.

\section{Menghitung Nilai Kredibilitas Rasio}

Penghitungan nilai kredibilitas pada penelitian ini menggunakan video likes to likes. Cara penghitungannya adalah dengan mengambil nilai rata variabel video likes yang kemudian dibagi jumlah likes akun tersebut. Jika dimisalkan jumlah rata video likes adalah 10000 dan total likes 300000, maka cara penghitungannya yaitu $10000: 300000$ $=0,03$. Dengan demikian nilai dari video likes to likes adalah 0,03.

\section{Menentukan Peringkat Pada Akun TikTok}

Langkah terakhir adalah menentukan peringkat dari akun TikTok Vendor Smartphone. Pada penentuan peringkat perlu melihat karakteristik dari rasio yang di teliti. Untuk memberikan peringkat pada masing-masing Vendor Smartphone, peneliti memberikan angka 1 kepada vendor yang mendapat nilai tertinggi dan angka 5 untuk vendor yang mendapat nilai terendah. 


\section{HASIL DAN PEMBAHASAN}

Akun TikTok dari Top 5 Vendor Smartphone di Indonesia Q2-2021, sebagai berikut :

\section{XIAOMI Indonesia}

$\leftarrow$

$\stackrel{0}{0} \quad$

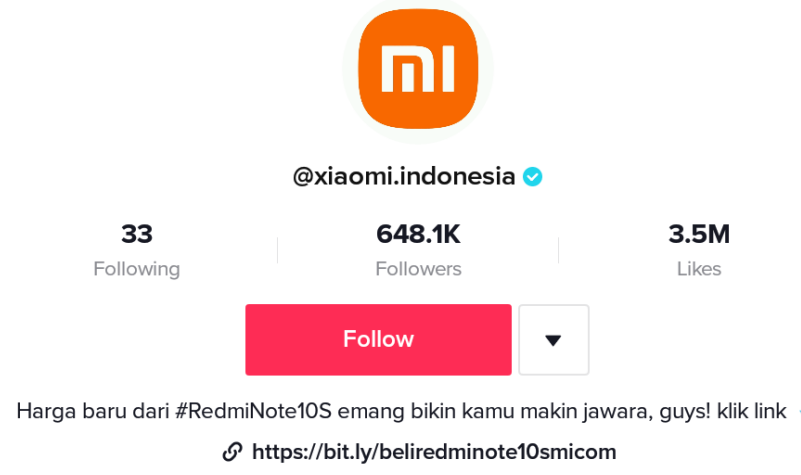

Gambar 4.1 Akun TikTok XIAOMI Indonesia

Sumber : https://www.tiktok.com/@XIAOMI.indonesia (akses 22-10-2021)

\section{Oppo Indonesia}

$\leftarrow$

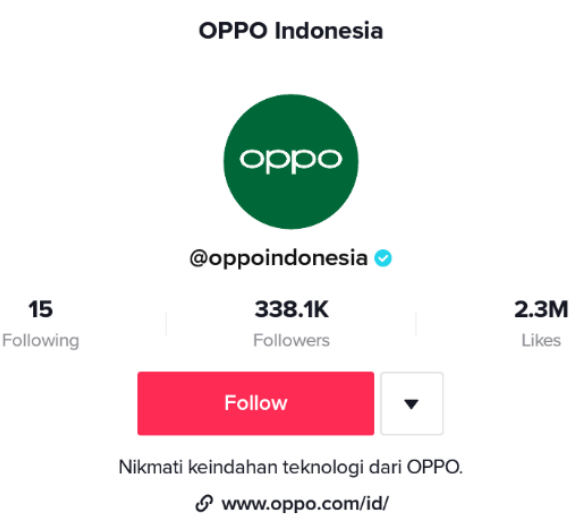

Gambar 4.2 Akun TikTok Oppo Indonesia

Sumber : https://www.tiktok.com/@oppoindonesia (akses 22-10-2021)

\section{Samsung Indonesia}
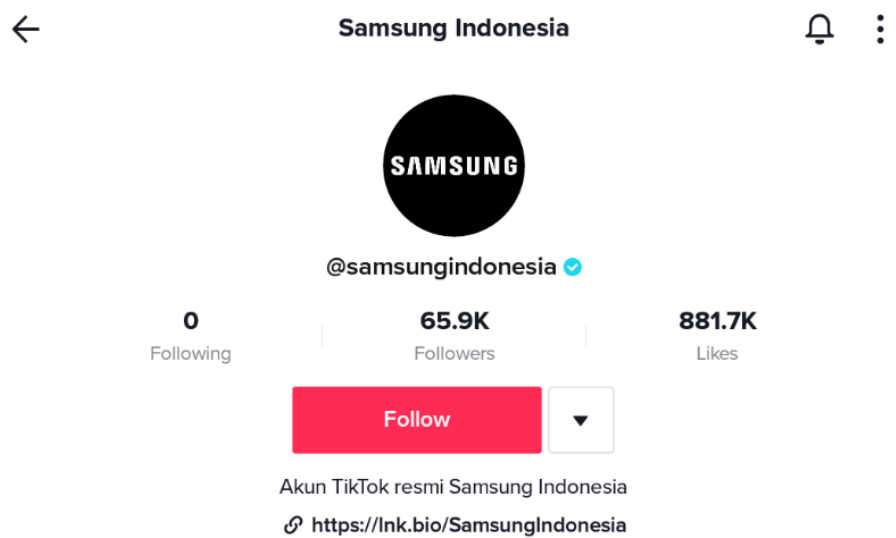

Gambar 4.3 Akun TikTok Samsung Indonesia

Sumber : https://www.tiktok.com/@samsungindonesia (akses 22-10-2021) 


\section{REALME Indonesia}

$\leftarrow$

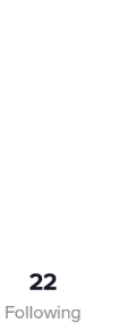

$\stackrel{0}{0}:$

887.1K

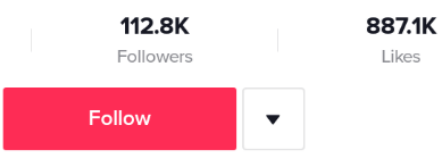

O realme.com/id

2] Q\&A

Gambar 4.4 Akun TikTok REALME Indonesia

Sumber : https://www.tiktok.com/@REALME.indonesia (akses 22-10-2021)

\section{VIVO Indonesia}

$\leftarrow$ vivo_indonesia

$\stackrel{0}{Q}:$

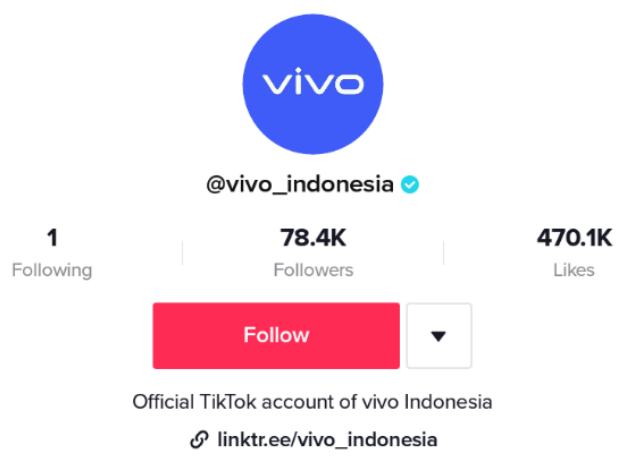

Gambar 4.5 Akun TikTok VIVO Indonesia

Sumber: https://www.tiktok.com/@VIVO_indonesia (akses 22-10-2021)

Dari kelima akun TikTok Top 5 Vendor Smartphone di Indonesia Q2-2021, ada beberapa nilai variabel yang ditemukan untuk menghitung rasio Video Likes to Likes dari setiap akun. Pada akun TikTok terdapat 7 variabel, yaitu :

1. Likes

2. Followers

3. Following

4. Video Likes

5. Video Comments

6. Video Share

7. Video Views

Dari ketujuh variabel tersebut peneliti hanya fokus untuk menemukan hasil dari 2 variabel, yaitu :

1. Likes

2. Video Likes

Dari kedua variabel tersebut kemudian dilakukan analisa sehingga menemukan nilai rata-rata dari variabel video likes dan total likes. Untuk menghitung nilai rata-rata dari variabel video likes dilakukan dengan mengambil 10 postingan kemudian di hitung sehingga menemukan nilai rata-rata. Berikut tabel nilai rata-rata video likes dan total likes masing-masing vendor smartphone di Indonesia, yaitu : 
Tabel 1. Analisa Nilai Rata-Rata Variabel Video Likes Akun TikTok XIAOMI Indonesia

\begin{tabular}{|c|r|}
\hline No. & Video Likes \\
\hline 1 & 90 \\
\hline 2 & 15.500 \\
\hline 3 & 102 \\
\hline 4 & 140 \\
\hline 5 & 31.500 \\
\hline 6 & 1.867 \\
\hline 7 & 114 \\
\hline 8 & 53 \\
\hline 9 & 25.800 \\
\hline 10 & 114 \\
\hline Total & $\mathbf{7 . 5 2 8}$ \\
\hline
\end{tabular}

Sumber : Pengelola Data Excel

Tabel 2. Analisa Nilai Rata-Rata Variabel Video Likes Akun TikTok Oppo Indonesia

\begin{tabular}{|c|r|}
\hline No. & Video Likes \\
\hline 1 & 140 \\
\hline 2 & 23.900 \\
\hline 3 & 633 \\
\hline 4 & 939 \\
\hline 5 & 186 \\
\hline 6 & 591 \\
\hline 7 & 333 \\
\hline 8 & 471 \\
\hline 9 & 24.500 \\
\hline 10 & 22.400 \\
\hline Total & $\mathbf{7 . 4 0 9}$ \\
\hline Sumber $:$ Pengelola Data Excel
\end{tabular}

Sumber : Pengelola Data Excel 
Tabel 3. Analisa Nilai Rata-Rata Variabel Video Likes Akun TikTok Samsung Indonesia

\begin{tabular}{|c|r|}
\hline No. & \multicolumn{1}{|c|}{ Video Likes } \\
\hline 1 & 6 \\
\hline 2 & 21 \\
\hline 3 & 13 \\
\hline 4 & 40 \\
\hline 5 & 47.400 \\
\hline 6 & 69 \\
\hline 7 & 160 \\
\hline 8 & 57.000 \\
\hline 9 & 59.200 \\
\hline 10 & 69.300 \\
\hline Total & $\mathbf{2 3 . 3 2 1}$ \\
\hline Sumber : Pengelola Data Excel
\end{tabular}

Tabel 4. Analisa Nilai Rata-Rata Variabel Video Likes Akun TikTok REALME Indonesia

\begin{tabular}{|c|r|}
\hline No. & Video Likes \\
\hline 1 & 1.047 \\
\hline 2 & 331 \\
\hline 3 & 1.623 \\
\hline 4 & 3.258 \\
\hline 5 & 3.217 \\
\hline 6 & 2.156 \\
\hline 7 & 7.764 \\
\hline 8 & 2.177 \\
\hline 9 & 3.867 \\
\hline 10 & 1.917 \\
\hline Total & $\mathbf{2 . 7 3 6}$ \\
\hline Sumber : Pengelola Data Excel
\end{tabular}


Tabel 5. Analisa Nilai Rata-Rata Variabel Video Likes Akun TikTok VIVO Indonesia

\begin{tabular}{|c|r|}
\hline No. & \multicolumn{1}{|c|}{ Video Likes } \\
\hline 1 & 715 \\
\hline 2 & 339 \\
\hline 3 & 182 \\
\hline 4 & 182 \\
\hline 5 & 294 \\
\hline 6 & 46.500 \\
\hline 7 & 30.700 \\
\hline 8 & 18.500 \\
\hline 9 & 151 \\
\hline 10 & 180 \\
\hline Total & $\mathbf{9 . 7 7 4}$ \\
\hline Sumber : Pengelola Data Excel
\end{tabular}

Tabel 5. Analisa Nilai Variabel Likes Akun TikTok 5 Brand Smartphone

\begin{tabular}{|l|r|}
\hline \multicolumn{1}{|c|}{ Brand } & \multicolumn{1}{c|}{ Likes } \\
\hline XIAOMI & 3.500 .000 \\
\hline Oppo & 2.300 .000 \\
\hline Samsung & 880.300 \\
\hline REALME & 870.200 \\
\hline VIVO & 469.800 \\
\hline \multicolumn{2}{|c|}{ Sumber : Pengelola Data Excel }
\end{tabular}

Setelah menghitung rata-rata dan total likes tersebut, maka akan menemukan hasil akhir nilai rata-rata variabel likes dan total likes sebagai berikut :

Tabel 6. Nilai Variabel Akun TikTok Top 5 Vendor Smartphone di Indonesia

\begin{tabular}{|l|r|l|r|r|r|}
\hline Variabel & XIAOMI & Oppo & Samsung & REALME & VIVO \\
\hline Video Likes & 7528 & 7409 & 23321 & 2736 & 9774 \\
\hline Likes & 3500000 & 2300000 & 881700 & 887100 & 470100 \\
\hline
\end{tabular}

Pada akun TikTok terdapat 17 rasio yang relevan digunakan untuk mengukur kredibilitas pada masing-masing akun. Namun pada penelitian ini hanya akan berfokus untuk menghitung Video Likes to Likes Rasio. Untuk menghitung kredibilitas dari masing-masing akun TikTok setiap vendor smartphone, peneliti menghitung dengan cara : variabel 1 akan dibagi variabel 2, sehingga ditemukan hasil analisa dari rasio tersebut. 
Tabel 7. Nilai Rasio Akun TikTok Top 5 Vendor Smartphone di Indonesia

\begin{tabular}{|l|c|r|}
\hline \multicolumn{1}{|c|}{ Brand } & Total & Peringkat \\
\hline XIAOMI & 0,00215086 & 5 \\
\hline Oppo & 0,00322143 & 3 \\
\hline Samsung & 0,02644993 & 1 \\
\hline REALME & 0,00308387 & 4 \\
\hline VIVO & 0,02079196 & 2 \\
\hline
\end{tabular}

Video Likes to Likes memiliki karakteristik yang tinggi, artinya semakin tinggi nilai yang dihasilkan maka semakin baik kredibilitas dari performa akun tersebut. Untuk memberikan peringkat pada masing-masing Vendor Smartphone, peneliti memberikan angka 1 kepada vendor yang mendapat nilai tertinggi dan angka 5 untuk vendor yang mendapat nilai terendah. Dari Tabel Nilai Rasio Akun TikTok Top 5 Vendor Smartphone di Indonesia dapat disimpulkan bahwa Samsung Indonesia mendapat nilai tertinggi untuk rasio Video Likes to Likes. Sedangkan XIAOMI Indonesia mendapat nilai terendah untuk rasio ini. Jadi, pada penelitian ini Samsung Indonesia memiliki kredibilitas performa yang paling baik dibandingkan dengan vendor smartphone lainnya. 


\section{KESIMPULAN}

Tujuan penelitian ini adalah untuk mengetahui kredibilitas dari akun TikTok Top 5 Vendor Smartphone di Indonesia menggunakan Video Likes to Likes Rasio. Top 5 Vendor Smartphone di Indonesia yaitu : XIAOMI Indonesia, Oppo Indonesia, Samsung Indonesia, REALME Indonesia dan VIVO Indonesia. Dari kelima vendor smartphone tersebut dapat disimpulkan bahwa :

1. Peringkat pertama diraih oleh vendor Samsung Indonesia dengan nilai tertinggi yaitu 0,02644993 .

2. Peringkat kedua diraih oleh vendor VIVO Indonesia dengan nilai 0,02079196.

3. Peringkat ketiga diraih oleh vendor Oppo Indonesia dengan nilai 0,00322143.

4. Peringkat keempat diraih oleh vendor REALME Indonesia dengan nilai 0,00308387.

5. Peringkat kelima diraih oleh vendor XIAOMI dengan nilai terendah yaitu 0,00215086. 


\section{DAFTAR PUSTAKA}

Adawiyah, D. P. R. (2020). Pengaruh Penggunaan Aplikasi TikTok Terhadap Kepercayaan Diri Remaja di Kabupaten Sampang. Jurnal Komunikasi, 14(2), 135-148. https://doi.org/10.21107/ilkom.v14i2.7504

Hilal Ramadhan, I., Priatama, R., Akalili, A., \& Kulau, F. (2021). Analisis Teknik Digital Marketing pada Aplikasi Tiktok (Studi Kasus Akun TikTok @jogjafoodhunterofficial) Analysis of Digital Marketing Techniques in Tiktok Aplication (Case Study of @jogjafoodhunterofficial). Online) Socia: Jurnal Ilmu-Ilmu Sosial, 18(1), 49-60.

I Putu Hendika Permana, \& Ni Putu Suci Meinarni. (2021). Ratio Analysis on Tiktok (Social Media) for Qualitative Research Using Explorative Methods. Jurnal Ekonomi \& Bisnis JAGADITHA, 8(1), 30-38. https://doi.org/10.22225/jj.8.1.2944.30-38

Indonesia Jadi Pasar Kedua Terbesar TikTok di Dunia pada 2020 | Databoks. (n.d.). Retrieved October 28, 2021, from https://databoks.katadata.co.id/datapublish/2021/09/29/indonesia-jadi-pasar-keduaterbesar-tiktok-di-dunia-pada-2020

Mudjiyanto, B. (2018). Tipe Penelitian Eksploratif Komunikasi. Jurnal Studi Komunikasi Dan Media, 22(1), 65. https://doi.org/10.31445/jskm.2018.220105

Putri, S. D., \& Azeharie, S. (2021). Strategi Pengelolaan Komunikasi dalam Membentuk Personal Branding di Media Sosial Tiktok. Koneksi, 5(2), 280. https://doi.org/10.24912/kn.v5i2.10300

Susilowati, A. K. B. J. (2018). Pemanfaatan Aplikasi Tiktok Sebagai Personal Branding Di Instagram (Studi Deskriptif Kualitatif Pada Akun @bowo_allpennliebe).Jurnal Komunikasi, 9(2), 176-185. http://ejournal.bsi.ac.id/ejurnal/index.php/jkom

Top 5 Vendor Smartphone di Indonesia Q2-2021 - Selular.ID. (n.d.). Retrieved October 28, 2021, from https://selular.id/2021/08/top-5-vendor-smartphone-di-indonesia-q2-2021/

Wijaya, M. H. dwi, \& Mashud, M. (2020). Konsumsi Media Sosial Bagi Kalangan Pelajar: Studi Pada Hyperrealitas TikTok. Al-Mada: Jurnal Agama, Sosial, Dan Budaya, 3(2), 170-191. https://doi.org/10.31538/almada.v3i2.734 